\title{
Establishing a specialist eating disorders team
}

\author{
Sophie Roberts, Toni Foxton, lan Partridge and Greg Richardson
}

\begin{abstract}
Child and adolescent mental health services operate at four tiers. An eating disorders service is a tier 3 function and in the usual absence of specific funding has to operate from within current resources. The operation of an eating disorders team within a wider child and adolescent mental health service has significant advantages. The operation of such a feam is explained and the advantages discussed.
\end{abstract}

The establishment or delineation of tier 3 teams within existing child and adolescent mental health services (CAMHSs) is recommended by Together We Stand (NHS Health Advisory Service, 1995). The tiered model is supported by the House of Commons Health Committee (1997). New resources are rarely available for the establishment of such teams so this paper looks at the establishment of a specialist eating disorders team within an existing CAMHS, utilising and rationalising existing resources.

CAMHSs routinely deal with referrals of young people with eating disorders both on an outpatient and an in-patient basis. As a specialist area, eating disorders are the subject of much debate with regard to both aetiology and treatment (Royal College of Psychiatrists, 1992; Ward et al, 1995). It is suggested that the establishment of a specialist service within the existing CAMHS offers a practicable and efficient service with the optimal use of resources of personnel and time. Such a specialist service affords a flexibility and continuity of care between outpatient and in-patient treatment regimes as well as practical advantages in terms of timetabling and the ability to offer a range of therapeutic interventions at a designated clinic.

\section{Establishing the team}

The principles upon which the eating disorders service is based are: (a) multi-disciplinary approaches are required; (b) a clear operational policy has been devised; (c) the service should respond promptly; (d) interventions should be geared to the individual needs of the young person and their family and the service should offer a range of interventions; and (e) there should be a continuum of care between outpatient and in-patient services.

A team of five comprising a consultant and trainee psychiatrist, a staff nurse from the inpatient service, a community psychiatric nurse and a social worker were considered to have the range of core skills and specialist training required. Training positions are available on the team. The establishment of the team was publicised to both general practitioners and other potential referrers.

A clinic operating for one session a week provides an initial assessment service as well as a variety of ongoing therapeutic interventions from various permutations of the team working individually and jointly. Flexdbility may entail the occasional working outside of this timetabled space. The team dealt with approximately 40 cases in its first year of operation.

\section{Referral and intervention}

All referrals to the CAMHS are processed via a weekly allocations meeting (Roberts \& Partridge, 1997). All young people referred with eating disorders, which include out of area requests for in-patient care, are allocated to the eating disorders team, as are young people passed on by other members of CAMHS. The eating disorders team discuss all referrals, prioritise them and allocate them to specific professionals. A standardised explanatory appointment is sent to the young person and their family. It is recognised that there may need to be emergency responses to acute crises; at times this may involve the involvement of other colleagues within the CAMHS. All initial appointments are offered within four weeks of referral.

At the initial assessment the whole family is requested to attend. A full history is taken, the young person has their height and weight measured and relevent physical examinations and investigations are performed. An eating attitude test is completed by the young person. An initial management plan is negotiated with the family taking into account developmental, physical and psychological considerations. The possible physical consequences of eating 
disorders may dictate medical treatment and therefore the team has been keen to establish close working relationships with colleagues in paediatrics, endocrine and gastro-enterological medicine.

The team offers a range of therapeutic options including advice on management (often based on behavioural principles), individual therapies (cognitive, behavioural, psychotherapeutic), motivational interviewing (Treasure \& Ward, 1997), guided reading (Schmidt \& Treasure, 1993), family therapy and if absolutely necessary inpatient treatment. Treatment programmes are tailored to meet the needs of the young person and their family.

The team's functioning is at present being audited externally by a research team at Hull University.

\section{Advantages and disadvantages of an integrated service}

Recently, there has been a move towards the establishment of discrete eating disorders services as a response to consumer pressure and a perception by providers that such services are income generators.

The advantages of a specialist eating disorders team operating within rather than without an existing CAMHS are:

(a) It offers coordinated utilisation of existing resources of personnel and time to provide a discrete and recognisable service.

(b) It allows team cohesion within the wider CAMHS, specialist expertise and experience not being hived off and isolated.

(c) It allows a clear bridge between the inpatient and out-patient services so facilitating a continuum as well as continuity of care by the same staff. A side-effect of such working is the reduction in in-patient admissions. (It is of note that in the first year of operation no local eating disorder case has required in-patient admission; we would suggest that the operation of the team has enhanced our confidence in community management strategies.)

(d) It avoids the fragmentation of services, with the offering of specialist resources within the context of an holistic mental health provision, recognising that eating disorders often exist within a wider clinical context and may be concomitant with other psychological or psychiatric dysfunction.

(e) It allows the development of expertise within team members which can be utilised to meet training needs and requirements for a range of disciplines as well as training programmes which can be offered to allied disciplines and in consultation to other agencies.

(f) It ensures the development of a coherent service with a model of treatment(s) informed from a multi-disciplinary perspective.

(g) The team composition and organisation offers a range and variety of treatment options as well as offering effective use of time so that individuals are seen speedily and regularly within the structure of a mutually supportive team. Supervison is built into the organisation of the team and can, if and when necessary, be live.

(h) Being part of a wider CAMHS means that practitioners do not become blinkered in outlook by operating entirely within the field of eating disorders, having always the advantages of a wider mental health perspective.

(i) It avoids problems of differential funding for different disorders. (This may be considered a disadvantage by those who put money making above comprehensive and integrated patient care).

(j) It is recognised that such specialist provision within an existing CAMHS is labour intensive and removes resources from existing service provision. However, these young people would still have to be managed by the service.

(k) Non-attendance can prove costly in terms of the allocation of team time, but a specific clinic whose purpose is well explained appears to reduce non-attendance rates.

(l) The team is acutely aware that pressure upon such a small-scale service could lead to the unwelcome lengthening of waiting lists, but if the team size and clinics are geared to the needs of the catchment population this should not be a problem.

\section{Conclusion}

A discrete, tier 3 eating disorders service operating as part of a CAMHS ensures skilled input for a group of young people and their families with very particular needs while ensuring that their other mental health needs are met within a comprehensive, integrated and accessible service.

\section{References}

House of Commons HeALTH Commrtee (1997) Child and Adolescent Mental Health Services. London: HMSO. 
NHS Health AdVISORY SERVICE (1995) Together We Stand The Commissioning. Role and Management of Child and Adolescent Mental Health Services (eds R. Williams \& G. Richardson). London: HMSO.

ROBERTS, S. \& PARTRIDGE, I. (1998). Allocation of referrals within a child and adolescent mental health team. Psychiatric Bulletin, in press.

Royal College of Psychiatrists (1992) Eating Disorders, Council Report CR14. London: Royal College of Psychiatrists.

SCHMIDT, U. \& TREASURE, J. (1993) Getting Better Bit(e) by Bit(e). Hillsdale. NJ: Lawrence Erlbaum Associates.

TREASURE, J. \& WARD, A. (1997). A practical guide to the use of motivational interviewing in anorexia nervosa. European Review of Eating Disorders, 6. 102-114.
WARD, A., RAMSEY, R. \& TREASURE, J. (1995) Eating disorders: not such a slim speciality. Psychiatric Bulletin, 19, 723-724.

Sophie Roberts, Registrar in Psychiatry, Toni Foxton, In-patient Nurse Manager, Ian Partridge, Social Worker, Greg Richardson Consultant Psychiatrist, Lime Trees, Child Adolescent and Family Unit, 31 Shipton Road, York YO3 6RE

*Correspondence

\section{So Young, So Sad, So Listen}

\section{By Philip Graham \& Carol Hughes}

Depression is one of the most common, serious problems in today's school-age population. However, it is only relatively recently, in the past 20 years or so, that it has become clear that a significant number of children and teenagers have such serious disturbances of mood that it is quite appropriate to think of them as having depressive disorders.

This book is about depression in children and teenagers during their school years, from 5 to 16 . It tries to explain ways that depression can be recognised by parents, teachers and the young themselves and explains what can be done to help.

\section{$£ 5.00 \bullet 56 p p . \bullet 1995 \bullet$ ISBN $090224180 \mathrm{X}$}

Available from bookshops and from the Publications Department, Royal College of Psychiatrists, 17 Belgrave Square, London SW1X 8PG (Tel. 0171-235 2351 extension 146) 